\title{
Development and validation of a self-control competency scale for late-school-aged children
}

\author{
Bo Kyoung Jin ${ }^{1}$, Hye Young $\mathrm{Ahn}^{2}$ \\ ${ }^{1}$ Instructor, College of Nursing, Eulji University, Daejeon; ${ }^{2}$ Professor, College of Nursing, Eulji University, Daejeon, Korea
}

Purpose: The aim of this study was to develop a self-control competency scale for school-aged children and to confirm its reliability and validity. Methods: This study involved methodological research to verify the reliability and validity of a self-control competency scale for school-aged children. Data were collected from 438 students in the fifth and sixth grades of elementary school. Results: The self-control competency scale was composed of 13 items and six subscales (control of relationship with one's teacher, problem-solving, peer empathy, control of relationships with one's peers, impulse control, and emotional control). The internal consistency reliability of the scale was evaluated using Cronbach's $\alpha$, which was .83 for the entire scale and ranged from .65 to .76 for the subscales. The model of six subscales was validated by CFA (CMIN/df=1.977; $p<.001$, GFI=.94, SRMR=.050, RMSEA=.065, IFI=.95, TLI=.93, CFI=.95). Concurrent validity was evaluated by comparing this scale to the scale developed by Nam and Ok (2000), and a significant correlation was found ( $\mathrm{r}=.82, p<.001)$. On this scale, higher scores indicate higher levels of self-control among late-school-aged children. Conclusion: This scale can be used as a valid and reliable instrument for examining self-control competency among late-school-aged children.

Key words: Self-control; Child; Validation study; Reproducibility of results

\section{INTRODUCTION}

\section{Corresponding author Hye Young Ahn \\ https://orcid.org/0000-0002-5353-671X}

College of Nursing, Eulji University,

77 Gyeryong-ro, 771 Beon-gil, Jung-gu, Daejeon 34824, Korea

TEL +82-42-259-1715 FAX +82-42-259-1709

E-MAIL ahanaya@eulji.ac.kr

*This article was adapted from a thesis by Bo Kyoung Jin in partial fulfillment of the requirements for the dissertation at Eulji University.

Received Aug 17, 2020 Revised Sep 15, 2020 Accepted Sep 16, 2020

(a) This is an Open Access article distributed under the terms of the Creative Commons Attribution NonCommercial License (http://creativecommons.org/licenses/by-nc/4.0/) which permits unrestricted noncommercial use, distribution, and reproduction in any medium, provided the original work is properly cited.

\section{Need for Study}

Self-control refers to the ability to control impulses when faced with challenges or temptations, and is closely related to physiological and psychological well-being [1]. Therefore, self-control is being studied in various fields, including nursing [2]. Self-control appears around the age of 4 years [3]. It develops gradually and steadily from middle to late childhood, concomitantly with cognitive growth [3]. In early research on this topic, parenting was suggested as an important factor influencing self-control [4], as experiences of positive parenting and strong parent-child relationships were associated with higher levels of self-control. Self-control is fundamental to cognitive abilities, such as decision-making and future planning, throughout life [5]. Adolescents with higher self-control than their peers are at a lower risk of developing problematic behaviors [6]. Low self-control in school-aged children is associated with substance dependence, alcohol and drug problems, and criminal behavior in adulthood [4,7]. Late childhood (ages 11-12 years) is the preadolescent period at the end of childhood and the beginning of adolescence. Therefore, self-control in late-school-aged children is closely related to self-control in adolescence and adulthood [7]. Furthermore, 
improvements in self-control are closely related to children's psychological well-being [4]. In order to improve self-control in children, it is necessary to be able to assess their level of self-control using a reliable and valid measurement scale.

Efforts to develop tools to measure self-control began with observations of children made by a teacher or parent. In addition, a method was developed of directly observing a child's behavior in response to a given situation, and a self-reporting scale was also subsequently developed [8,9]. The most commonly used scale is the self-control measurement scale of Gottfredson and Hirschi [4]. This is a 20-item 5-point Likert-scale instrument evaluating long-term satisfaction-seeking and immediate satisfaction-seeking; as such, it measures self-control in terms of delayed satisfaction. However, for the Korean version of this scale, internal consistency reliability has only been confirmed for middle school students [6].

The self-control scale developed by Grasmick et al. [10] for college students is composed of sub-attributes of impulsivity, simple tasks, risk seeking, physical activities, self-centered, and temper. In this scale, emotional control includes only anger, not interpersonal relationships. The internal consistency reliability of this scale was presented upon its development. The low self-control scale developed by Tangney et al. [11] measures self-control in terms of achievement and task performance, impulse control, adjustment, interpersonal relationships, moral emotion, and related personality features. This scale mainly deals with the influence and measurement of low self-control and the emotional domain contains only moral aspects.

In Korea, a 43-item scale was developed through field research among elementary school students [12]. This scale is meaningful in that it closely reflects the context of elementary schools in Korea, as it was developed through a field investigation. Internal consistency reliability and validity were presented in terms of expert content validity and convergent validity. However, it is necessary to conduct additional field research to check whether there are any differences in the characteristics of self-control between the past and today, and the number of questions in this tool is somewhat large for it to be administered to elementary-school students. Late-schoolaged children are in a period of developmental change [3]. Today's school-aged children are in need of more self-control competency than in the past due to the increased ownership of smartphones, as well as alcohol and drug problems [13]. Therefore, it is necessary to develop a scale with high validity and reliability to reflect the current characteristics of self-control among late-school-aged children.

The scales described above have been used to measure self-control. However, 15 to 30 years have passed since these instruments were developed, and changes over time in the sit- uations requiring self-control have yet to be reflected in the available instruments. The measurement of self-control needs to be based on prompts appropriate to the times. Previously developed scales also differ from each other in terms of measurements. Scales developed on a theoretical basis need to be verified in the field. In addition, for scales developed only through field studies, research is needed to validate whether the characteristics described in the literature are confirmed in the field. Furthermore, for translated scales, the sub-factors of the original scales are reduced and the target population of the measurement scale is different [11,14]. Self-control competency is an abstract and complex aspect of human psychology. Therefore, a valid and reliable measurement scale is needed to quantify its characteristics in detail. This study examined the characteristics and attributes of late-school-aged children's self-control competency through a review of the literature and field surveys, and based on this, developed a self-reporting self-control competency scale for late-school-aged children and verified its validity and reliability.

\section{Purpose}

The purpose of this study was to develop a self-control competency measurement scale for late-school-aged children and to verify its reliability and validity.

\section{Definition of the Concept}

Self-control competency refers to the ability to control one's own behaviors as appropriate for a given situation and to refrain from impulsive behavior or immediate satisfaction in order to obtain better results in the future [12]. This conceptual construct is measured using the self-control competency scale for late-school-aged children developed by the researchers in this study.

\section{METHODS}

\section{Study Design}

This study was conducted in eight steps using the scale development procedure presented by DeVellis [15]. This methodological study was carried out to develop a self-control competency measurement scale for late-school-aged children and to verify its reliability and validity (Figure 1).

\section{Scale Development Process}

\section{1) Derivation of preliminary items}

In order to confirm the properties of late-school-aged chil- 


\begin{tabular}{|c|c|c|c|}
\hline Aim & \multicolumn{2}{|c|}{ Steps } & Detailed contents \\
\hline \multirow{7}{*}{$\begin{array}{l}\text { Development } \\
\text { of scale }\end{array}$} & \multirow[t]{2}{*}{ Components of scale } & Literature review & $\begin{array}{l}\text { Article review (91) } \\
\text { (Korean studies 38, international studies } 53 \text { ) }\end{array}$ \\
\hline & & Focus group interview & Elementary school students $(n=20)$ \\
\hline & Item preparation & $\begin{array}{l}\text { Preliminary item } \\
\text { composition } \\
\text { (92 items) }\end{array}$ & $\begin{array}{l}\text { Developing and reviewing items by derived } \\
\text { components } \\
\text { Review of literature }(120 \text { items) and group } \\
\text { interview ( } 23 \text { items) } \\
\text { Excluded } 51 \text { overlapping items } \rightarrow \text { preliminary } \\
\text { items ( } 92 \text { items) }\end{array}$ \\
\hline & Selection of a response format & Likert scale & 5-point Likert scale \\
\hline & Contont uolidity the & Content validity test & First test of content validity $(\mathrm{n}=6):(\mathrm{I}-\mathrm{CVI}>.80)$ \\
\hline & & by exports & Second test of content validity $(n=2)$ \\
\hline & Item review & Pilot test (63 items) & Participants $(n=22)$ \\
\hline \multirow{5}{*}{$\begin{array}{l}\text { Verification } \\
\text { of scale }\end{array}$} & Application of scale & Main survey & Participants $(n=438)$ \\
\hline & \multirow{3}{*}{ Evaluation of scale } & \multirow[t]{2}{*}{$\begin{array}{l}\text { Validity test } \\
\qquad(63 \rightarrow 62 \text { items })\end{array}$} & $\begin{array}{l}1 \text { item excluded by item analysis } \\
\text { Construct validity: } \\
\text { - Exploratory factor analysis }(n=200) \\
\text { - Confirmatory factor analysis }(n=238)\end{array}$ \\
\hline & & & Criterion-related validity: Concurrent validity \\
\hline & & $\begin{array}{l}\text { Reliability test } \\
\text { Test-retest ( } 62 \text { items) }\end{array}$ & $\begin{array}{l}\text { Internal consistency reliability } \\
\text { Intraclass correlation coefficient }(\mathrm{n}=30) \text { : } \\
\quad(\mathrm{ICC}=.843, p<.001)\end{array}$ \\
\hline & Optimization of scale & Final scale (13 items) & Final scale confirmation \\
\hline
\end{tabular}

Figure 1. Scale development process. I-CVI, item-content validity index; ICC, intraclass correlation coefficient.

dren's self-control competency, a hybrid model was applied combining a literature review and field survey [16]. First, the literature review analyzed domestic and international literature published from January 2010 to April 2020. For the literature search, the Core, Standard, Ideal (COSI) model proposed by the National Library of Medicine was applied [17]. The keywords were "self-control", "self-regulation", and "children". To review the international literature, the MeSH keyword "selfcontrol" was searched. For a more detailed search, "self-control" and "children" were selected.

Second, focus group interviews were conducted among 20 elementary school students in fifth to sixth grade. The interviews were conducted in four groups and lasted, on average, for 25 minutes. The interviews were stopped when the participants no longer spoke or when there were duplicate opinions in response to the following open-ended questions: "What do you think self-control is?", "In what cases have you experienced self-control?", and "In what cases did you need self-control?". The contents of the interview were recorded and transcribed with the consent of the participants and their legal guardians.

\section{2) Content validity}

Content validity was evaluated twice to test whether the 92 items preliminarily extracted from previous scales properly included the content to be measured. Content validity was ini- 
tially evaluated by two professors of pediatric nursing, one middle school health teacher, one elementary school health teacher, one elementary school teacher, and one nursing researcher with experience in scale development, totaling six persons. The content validity index (CVI) was calculated using a structured questionnaire [18]. The second round of content validity testing was conducted by one professional psychiatric nurse and one high school Korean language teacher as experts. Their opinions were reflected in the study through in-depth interviews.

\section{3) A pilot test}

A pilot test was conducted to revisit the feasibility of the study and the form and method of data collection. The degree of understanding of each item, the length of each item, the font and font size of the items, the method of displaying the response, the placement of each item, and participants' degree of understanding were investigated with an open-ended questionnaire.

\section{Scale Evaluation Process: Validity and Reliability Verifi- cation}

\section{1) Participants}

The criteria for inclusion were students in the fifth and sixth grades of elementary school in three metropolitan cities. Participants were required to understand the content of this study, to listen to an explanation of the purpose of the study, and to agree to participate with informed consent from their guardians. A pilot study was conducted with 22 participants based on the same inclusion criteria [19]. This survey attempted to collect data from 460 people considering a dropout rate of $15 \%$, but data from 451 people were finally collected. Data from 438 participants without missing values were analyzed, after the exclusion of data from 13 participants who provided insufficient responses.

To evaluate test-retest reliability, data were collected from 30 people through convenience sampling among the participants of this survey in May 2020.

\section{2) Data collection and ethical considerations}

The data collection period was from December 3, 2019 to May 11, 2020.This study was conducted after receiving approval (EU19-95) from the Institutional Review Board of Eulji University. After explaining to the participants that they could withdraw if they chose not to participate voluntarily, informed consent was obtained from the legal guardian and the participants.

\section{3) Data analysis}

Data analysis was performed using SPSS/WIN 25.0 (IBM Corp., Armonk, NY, USA) with the AMOS module. First, the general characteristics of the participants were presented in terms of frequency and percentage. The homogeneity of the exploratory factor analysis (EFA) group and the confirmatory factor analysis (CFA) group was tested using the $x^{2}$ test. Second, the CVI was calculated to evaluate content validity. Third, in the item analysis, the mean, standard deviation (SD), skewness, and kurtosis were checked to quantify the bias of each item. For the distribution of the total score, the floor effect and the ceiling effect were assessed.

Fourth, EFA and CFA were performed to confirm construct validity [19]. For EFA, principal component analysis and varimax rotation were used, and Kaiser-Meyer-Olkin (KMO) values and Bartlett's sphericity were calculated. The number of factors was determined through eigenvalues and cumulative variance percentage. The CFA confirmed the model fit through an absolute fit index and an incremental fit index (IFI). The $x^{2}$ statistic as an indicator of absolute fit, the normed $x^{2}$ statistic (chi-square minimum/degrees of freedom; CMIN/df), goodness-of-fit index (GFI), root mean square residual (RMR), standardized root mean square residual (SRMR), and root mean square error of approximation (RMSEA) were calculated. Model fit was confirmed through the IFI, Tucker-Lewis index (TLI or $\mathrm{NNFI}$ ), and the comparative fit index (CFI).

Fifth, the convergent validity and discriminant validity were checked. Item convergence was tested by the standardized lambda value, average variance extracted (AVE), and conceptual reliability $(\mathrm{CR})$. Discriminant validity was tested with the AVE, correlation coefficient $(\rho)$ and standard error (SE). Concurrent validity was analyzed by Pearson correlation coefficients between scales.

Internal consistency reliability was analyzed using Cronbach's $\alpha$, and test-retest reliability was analyzed by the intraclass correlation coefficient (ICC) [20]. At least 2 weeks after the main survey, 30 participants who had completed the in main survey were retested to calculate the ICC [21].

\section{4) Measurement scale}

In several studies, the self-control scale developed by Nam and Ok [6] has been utilized to measure self-control [22]. This scale consists of 10 items for delayed gratification and 10 items for immediate gratification. Higher delayed gratification scores and lower immediate gratification scores indicate higher selfcontrol competency [6]. The attributes assessed by this scale include impulse control, emotional control, deliberation, and interpersonal relations, similar to the attributes evaluated by the scale developed in this study. Permission was obtained from the developer via email before the scale was used in this study. 


\section{RESULTS}

\section{Development of the Scale}

\section{1) Components of the scale and item preparation}

First, a literature review was conducted to analyze the domestic and international literature. The number of domestic documents searched was 644 . After excluding duplicates and reviewing titles, abstracts, and texts, 38 original articles were finally selected, of which one described scale development, four dealt with translation of a scale from a foreign language, and 33 papers confirmed the use of a previously developed scale. From the international literature review, 392 documents were identified and 53 were selected, of which 51 were original articles and two were meta-analyses. Of the 51 original articles, one was a concept analysis, one was a theoretical study, three reported scale development, and forty-six confirmed the application of a previously developed scale. From the domestic and international literature, 120 items corresponding to five attributes were derived.

Second, focus group interviews were conducted among 20 fifth- to sixth-grade elementary school students, yielding 23 items; the 120 items derived from the literature and the 23 items derived through focus group interviews were combined to obtain a total of 143 tentative items. The preliminary scale was composed of a total of 92 items, excluding duplicates among the derived items.

\section{2) Selection of a response format}

The Likert scale is commonly used in nursing research [19]. In this study, a neutral category was suggested to ensure convenience of the participant's responses [21]. A 5-point Likert scale was chosen, with scores of strongly disagree (1), disagree (2), neutral (3), agree (4), and strongly agree (5).

\section{3) Content validity testing}

In the first round of content validity testing, the CVI was .50 points for two items, .67 points for 27 items, .83 points for 16 items, and 1.0 points for 47 items. This resulted in 63 items with a CVI of .80 or higher.

The second round of content validity testing was conducted by two experts. A psychiatric nurse was interviewed to determine whether the sub-attributes were appropriate for representing the attributes of the concept to be measured, and the opinions of the nurse were collected. A high school Korean language teacher evaluated whether each item was appropriate for measuring the concept and whether it was expressed in a way that the participants would understand clearly. After the first and second rounds of content validity, 63 items remained.

\section{4) Item review}

In the pilot test, data from 22 participants were analyzed. They answered that the items were appropriate in terms of their comprehensibility, length, font and font size, the method of displaying the response, and the placement of the item. As a minority opinion, one elementary school student responded that similar questions about development scales and existing scales were repetitive. No items were corrected or deleted as a result of the pilot test.

\section{Verification of the Scale}

\section{1) Application of the scale}

The general characteristics of participants in this study were as follows. Of the participants, $186(42.5 \%)$ were in the fifth grade, $252(57.5 \%)$ were in the sixth grade, $203(46.3 \%)$ were girls, and 235 (53.7\%) were boys. Regarding religious affiliation, 193 participants (44.1\%) reported "yes" and 245 (55.9\%) replied "no". The fathers of 118 participants $(26.9 \%)$ had completed a graduate education and those of 223 participants (50.9\%) had completed an undergraduate education. The mothers of 104 participants $(23.7 \%)$ had completed a graduate education and those of 240 participants (54.8\%) had completed an undergraduate education. The majority of participants $(\mathrm{n}=$ $323,73.7 \%$ ) responded that their family's socioeconomic status was "middle," while $102(23.3 \%)$ responded with "high". For self-perceived health status, $342(78.1 \%)$ participants stated that they were "healthy" and 89 (20.3\%) indicated that their health was "moderate". Using Microsoft Excel (Microsoft Corp., Redmond, WA, USA), 200 samples for EFA and 238 samples for CFA were randomly selected [21,23]. Statistical homogeneity of the EFA and CFA groups in terms of general characteristics was confirmed (Table 1).

\section{2) Evaluation of the scale}

(1) Item analysis

The average score of each of the 63 initial items was 2.984.65 points, and the standard deviation was 0.63-1.22. The absolute value of skewness of item 29 was 2.22 and the absolute value of kurtosis was 4.28 . In addition, for item 29 , the ceiling effect was $44.6 \%$. This item was excluded because it exceeded the skewness absolute value standard of 2 and the ceiling effect standard of less than $30 \%$. For the remaining 62 items, the absolute value of skewness of the items was $0.00-1.52$ points, the absolute value of kurtosis was 0.01-2.48 points, the floor effect was $0.0 \%-6.4 \%$, and the ceiling effect was $2.6 \%-29.0 \%$ [23]. The appropriateness of the scale containing 62 items, excluding item 29, was therefore verified.

(2) Exploratory factor analysis 
Table 1. General Characteristics of the Focus Group Participants $(N=438)$

\begin{tabular}{|c|c|c|c|c|c|c|}
\hline \multirow{2}{*}{ Variable } & \multirow{2}{*}{ Categories } & \multirow{2}{*}{$\mathrm{n}(\%)$} & EFA group $(n=200)$ & CFA group $(n=238)$ & \multirow{2}{*}{$x^{2}$} & \multirow{2}{*}{$p$} \\
\hline & & & $\mathrm{n}(\%)$ & $\mathrm{n}(\%)$ & & \\
\hline \multirow{2}{*}{ Grade } & 5 th & $186(42.5)$ & $82(41.0)$ & $104(43.7)$ & \multirow{2}{*}{0.32} & \multirow{2}{*}{.628} \\
\hline & 6th & $252(57.5)$ & $118(59.0)$ & $134(56.3)$ & & \\
\hline \multirow[t]{2}{*}{ Gender } & Female & $203(46.3)$ & $96(48.0)$ & $107(45.0)$ & \multirow[t]{2}{*}{0.40} & \multirow[t]{2}{*}{.564} \\
\hline & Male & $235(53.7)$ & $104(52.0)$ & $131(55.0)$ & & \\
\hline \multirow{2}{*}{ Religion } & Yes & $193(44.1)$ & $86(43.0)$ & $107(45.0)$ & \multirow[t]{2}{*}{0.17} & \multirow[t]{2}{*}{.700} \\
\hline & No & $245(55.9)$ & $114(57.0)$ & $131(55.0)$ & & \\
\hline \multirow{4}{*}{$\begin{array}{l}\text { Father's } \\
\text { education }\end{array}$} & Graduate & $118(26.9)$ & $49(24.5)$ & $69(29.0)$ & \multirow[t]{4}{*}{1.95} & \multirow[t]{4}{*}{.584} \\
\hline & Undergraduate & $223(50.9)$ & $108(54.0)$ & $115(48.3)$ & & \\
\hline & High school & $44(10.1)$ & $21(10.5)$ & $23(9.7)$ & & \\
\hline & Unknown & 53 (12.1) & $22(11.0)$ & $31(13.0)$ & & \\
\hline \multirow{4}{*}{$\begin{array}{l}\text { Mother's } \\
\text { education }\end{array}$} & Graduate & $104(23.7)$ & $47(23.5)$ & $57(23.9)$ & \multirow[t]{4}{*}{0.34} & \multirow[t]{4}{*}{.953} \\
\hline & Undergraduate & $240(54.8)$ & $111(55.5)$ & $129(54.2)$ & & \\
\hline & High school & $41(9.4)$ & $17(8.5)$ & $24(10.1)$ & & \\
\hline & Unknown & $53(12.1)$ & $2512.5)$ & $28(11.8)$ & & \\
\hline \multirow{3}{*}{$\begin{array}{l}\text { Economic } \\
\text { status }\end{array}$} & High & $102(23.3)$ & $48(24.0)$ & $54(22.7)$ & \multirow[t]{3}{*}{1.25} & \multirow[t]{3}{*}{.536} \\
\hline & Middle & $323(73.7)$ & $148(74.0)$ & $175(73.5)$ & & \\
\hline & Low & $13(3.0)$ & $4(2.0)$ & $9(3.8)$ & & \\
\hline \multirow{3}{*}{$\begin{array}{l}\text { Perceived } \\
\text { health }\end{array}$} & Healthy & $342(78.1)$ & $154(77.0)$ & $188(79.0)$ & \multirow[t]{3}{*}{0.33} & \multirow[t]{3}{*}{.848} \\
\hline & Moderate & $89(20.3)$ & $43(21.5)$ & $46(19.3)$ & & \\
\hline & Poor & $7(1.6)$ & $3(1.5)$ & $4(1.7)$ & & \\
\hline
\end{tabular}

CFA, confirmatory factor analysis; EFA, exploratory factor analysis.

First, EFA of 62 items was conducted, excluding one item as mentioned above. The KMO value was .50 or less, and the p-value of Bartlett's sphericity test was less than .050 [23]. The KMO value of the first EFA was .83 and the result of Bartlett's sphericity test was $5497.19(p<.001)$. The number of sub-factors extracted was 19 and the cumulative explanatory power was $69.38 \%$. Seven items with a factor loading less than .40 were excluded, as were 16 items with a difference of less than .20 in the cross-loading [24]. In addition, two items consisting of a single factor were excluded as an item.

In the secondary factor analysis, the number of sub-factors was 11 , totaling 37 items. Seven items with a difference of less than .20 in the cross-loading were excluded. The number of sub-factors for the third factor analysis was 10, with a total of 30 items. Four items with a difference of less than .20 in the cross-loading were excluded. In the fourth analysis, the number of sub-factors was 8 and there were 26 items. One item with a factor load less than .40 was deleted, and one item with a cross-loading of less than .20 was excluded.

In the fifth round of factor analysis, eight sub-factors and 24 items were derived. The item exclusion criteria excluded items 9 and 10, which were judged to be difficult-to-explain sub-attributes based on content review. The excluded items were item 9 ("Other people say I am a considerate person") and item 10 ("When I have to do what I want to do, I think about good things after doing it"). In the sixth round of factor analysis, seven sub-factors and 22 items were derived. Two items with cross-loading of less than .20 were excluded. The number of sub-factors in the seventh round of factor analysis was seven, with 20 items. Six items with a factor load of less than .70 were excluded, and one item with a factor load of less than .40 was excluded.

Therefore, 13 items with six attributes were derived. In the final (eighth) round of factor analysis, the KMO value was .72 and the value yielded by Bartlett's sphericity test was 736.23 $(p<.001)$. The sub-factors were "control of relationship with one's teacher", "problem-solving", "peer empathy", "control of relationships with one's peers", "impulse control", and "emotional control". The cumulative explanatory power was $76.82 \%$. The range of factor loading was .696-.875 (Table 2).

(3) Confirmatory factor analysis

The absolute fitness index, CMIN $\left(x^{2}\right)$, was $99.845(p<.001)$. The SRMR was .050, RMSEA was .065, GFI was .94, and AGFI was .90. The IFI was .95, TLI (=NNFI) was .93, and CFI was .95 (Table 3). In this study, the standardized coefficient $(\lambda)$ of 13 items, which is the result of the final EFA, was .563-.896. Item convergence validity was determined based on an AVE of .50 
Table 2. Results of Exploratory Factor Analysis $(N=200)$

\begin{tabular}{|c|c|c|c|c|c|c|c|}
\hline \multirow{2}{*}{ No } & \multirow{2}{*}{ Item contents } & \multicolumn{6}{|c|}{ Factor } \\
\hline & & $1^{\dagger}$ & $2^{\dagger}$ & $3^{\S}$ & $4^{\|}$ & $5^{\natural}$ & $6^{\#}$ \\
\hline 1 & I run in the hallway unless the teacher sees it.* & .831 & .078 & .121 & -.039 & .132 & .057 \\
\hline 2 & I do something else in class without the teacher's knowledge.* & .824 & .020 & .093 & .174 & .072 & .160 \\
\hline 3 & I tend to follow the rules well even when the teacher is not watching. & .696 & .305 & -.054 & .347 & .050 & .043 \\
\hline 4 & I can put up with difficult problems. & .109 & .870 & .057 & .139 & .070 & .071 \\
\hline 5 & I can finish things that are boring or not fun. & .128 & .844 & .134 & .090 & .068 & .157 \\
\hline 6 & I don't express my happiness to my friends when I'm complimented one-on-one. & -.054 & .037 & .875 & .206 & .162 & -.001 \\
\hline 7 & I show off to my friends when my test scores are good.* & .233 & .156 & .841 & .039 & .021 & .119 \\
\hline 8 & I cooperate well at group activities when I collaborate with my friends. & .096 & .109 & .033 & .860 & .095 & .102 \\
\hline 9 & When I talk with my friends, I listen to what other friends are saying. & .193 & .126 & .248 & .789 & .058 & .070 \\
\hline 10 & $\begin{array}{l}\text { Although I want to play longer than the set time, I can stop playing the game } \\
\text { (on the computer). }\end{array}$ & .062 & .065 & .061 & .064 & .874 & .077 \\
\hline 11 & I tend to follow time limits for using my smartphone. & .145 & .067 & .106 & .082 & .828 & .139 \\
\hline 12 & I am easily excited about small things.* & .047 & .163 & -.001 & .087 & .034 & .863 \\
\hline 13 & I express myself immediately when I feel good or bad.* & .171 & .055 & .117 & .078 & .203 & .798 \\
\hline \multicolumn{2}{|c|}{ Eigenvalue } & 3.901 & 1.421 & 1.345 & 1.252 & 1.047 & 1.022 \\
\hline \multicolumn{2}{|c|}{ Explained variance (\%) } & 15.713 & 12.782 & 12.388 & 12.386 & 12.041 & 11.514 \\
\hline \multicolumn{2}{|c|}{ Accumulative variance (\%) } & 15.713 & 28.495 & 40.883 & 53.269 & 65.309 & 76.824 \\
\hline \multicolumn{2}{|c|}{ Cronbach's $\alpha$ (total $=.80)$} & .76 & .75 & .73 & .68 & .70 & .65 \\
\hline \multicolumn{8}{|c|}{$\mathrm{KMO}=.72 ;$ Bartlett's test of sphericity $=736.23(p<.001)$} \\
\hline
\end{tabular}

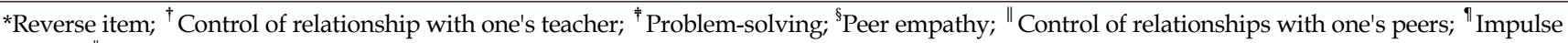
control; "Emotional control; KMO, Kaiser-Meyer-Olkin.

or higher and a CR of .70 or higher [25].

The AVE values of the six sub-factors of the scale developed in this study were .50 for control of relationship with one's teacher, .62 for problem-solving, .56 for peer empathy, .74 for control of relationships with one's peers, .56 for impulse control, and .49 for emotional control. The CR was .75 for control of relationship with one's teacher, .77 for problem-solving, .72 for peer empathy, .85 for control of relationships with one's peers, .72 for impulse control, and .65 for emotional control. The first result of discriminant validity was that the AVE was larger than the squared value of the correlation coefficient (Table 3). In another method of discriminant validity testing (correlation coefficient $\pm 2 \times \mathrm{SE}$ ), the absolute value should not include 1 [26]. Secondary discrimination validity was confirmed in this study (Table 4).

\section{(4) Concurrent validity}

The reliability of the self-control measurement scale developed by Nam and Ok [6] was evaluated using Cronbach's $\alpha$, which was .78 at the time of development and .88 in this study. The correlation between the total score of the scale developed in this study, and Nam and Ok's self-control scale [6] was .82 $(p<.001)$.
(5) Reliability test

As a measure of overall reliability, Cronbach's $\alpha$ of all 13 items for measuring the self-control competency of late-school -aged children developed in this study was $.83(n=438)$ [21]. Cronbach's $\alpha$ for each sub-factor was .76 for control of relationship with one's teacher, .75 for problem-solving, .73 for peer empathy, .68 for control of relationships with one's peers, .70 for impulse control, and .65 for emotional control (Table 2). Test-retest reliability was re-evaluated among the same participants two weeks later $[19,21]$. The ICC was $.843(p<.001)$ in $95 \%$ of the confidence intervals (Figure 1).

\section{3) Optimization of the scale}

As a step to optimize the self-control competency scale of late-school-aged children, the grammar and readability of the final selected items were modified based on advice from one nursing professor, one high school Korean language teacher, and one elementary school teacher with experience in scale development.

Two items were revised in the area of control of relationship with one's teacher. The item was revised from "I run in the corridor if the teacher does not see" to "I run in the hallway unless the teacher sees it". Additionally, "I play pranks if my 
Table 3. Result of Convergent Validity and First Test of Discriminant Validity, Model Fit of Confirmatory Factor Analysis $(N=238)$

\begin{tabular}{|c|c|c|c|c|c|c|c|c|c|c|c|c|}
\hline \multirow{2}{*}{$\begin{array}{l}\text { Factors } \\
\begin{array}{l}\text { 1. Control of relationship } \\
\text { with one's teacher }\end{array}\end{array}$} & \multicolumn{2}{|l|}{$\begin{array}{c}1 \\
\rho\left(\rho^{2}\right) \\
(p)\end{array}$} & $\begin{array}{c}2 \\
\rho\left(\rho^{2}\right) \\
(p)\end{array}$ & $\begin{array}{c}3 \\
\rho\left(\rho^{2}\right) \\
(p)\end{array}$ & \multicolumn{2}{|c|}{$\begin{array}{c}4 \\
\rho\left(\rho^{2}\right) \\
(p)\end{array}$} & \multicolumn{2}{|c|}{$\begin{array}{c}5 \\
\rho\left(\rho^{2}\right) \\
(p)\end{array}$} & \multicolumn{2}{|l|}{$\begin{array}{c}6 \\
\rho\left(\rho^{2}\right) \\
(p)\end{array}$} & AVE & CR \\
\hline & 1 & & & & & & & & & & .50 & .75 \\
\hline 2. Problem-solving & $\begin{array}{r}.559(.31 \\
(.001)\end{array}$ & & 1 & & & & & & & & .62 & .77 \\
\hline 3. Peer empathy & $\begin{array}{r}.427(.18 \\
(.001)\end{array}$ & & $\begin{array}{c}.437(.191) \\
(.002)\end{array}$ & 1 & & & & & & & .56 & .72 \\
\hline $\begin{array}{l}\text { 4. Control of relationship } \\
\text { with one's peers }\end{array}$ & $\begin{array}{r}.547(.29 \\
(.002)\end{array}$ & & $\begin{array}{c}.477(.228) \\
(.001)\end{array}$ & $\begin{array}{c}.580(.336) \\
(.001)\end{array}$ & 1 & & & & & & .74 & .85 \\
\hline 5. Impulse control & $\begin{array}{r}.672(.45 \\
(.001)\end{array}$ & & $\begin{array}{c}.575(.331) \\
(.001)\end{array}$ & $\begin{array}{c}.495 .245) \\
(.001)\end{array}$ & $\begin{array}{r}.449( \\
\quad .00\end{array}$ & $\begin{array}{l}\text { 202) } \\
1)\end{array}$ & & 1 & & & .56 & .72 \\
\hline 6. Emotional control & $\begin{array}{r}.519(.26 \\
(.001)\end{array}$ & & $\begin{array}{c}.447(.200) \\
(.001)\end{array}$ & $\begin{array}{c}.219(.048) \\
(.040)\end{array}$ & $\begin{array}{r}.208( \\
\quad .07\end{array}$ & 8) & .43 & $\begin{array}{l}(.193) \\
.001)\end{array}$ & 1 & & .49 & .65 \\
\hline \multirow{2}{*}{ Fitness index } & \multicolumn{3}{|c|}{ CMIN } & \multirow{2}{*}{$\mathrm{CMIN} / \mathrm{df}$} & \multirow{2}{*}{ SRMR } & \multirow{2}{*}{\multicolumn{2}{|c|}{ RMSEA }} & \multirow{2}{*}{ GFI } & \multirow{2}{*}{ AGFI } & \multirow{2}{*}{ IFI } & \multirow{2}{*}{ TLI } & \multirow{2}{*}{ CFI } \\
\hline & CMIN & $\mathrm{df}$ & $p$ & & & & & & & & & \\
\hline Criteria & & & $>.050$ & $<3.000$ & $\leq .080$ & .050 & .080 & $\geq .90$ & $\geq .90$ & $\geq .90$ & $\geq .90$ & $\geq .90$ \\
\hline Model & 99.845 & 50 & $<.001$ & 1.997 & .050 & & & .94 & .90 & .95 & .93 & .95 \\
\hline
\end{tabular}

Table 4. Results of the Second Test of Discriminant Validity $(N=238)$

\begin{tabular}{|c|c|c|c|c|c|c|c|}
\hline & \multirow{2}{*}{ Factors } & & \multirow{2}{*}{$\rho$} & \multirow{2}{*}{ SE } & \multicolumn{3}{|c|}{$\rho \pm 2 \times S E$} \\
\hline & & & & & $2 \times S E$ & - & + \\
\hline $\mathrm{CT}$ & $\leftrightarrow$ & Problem-solving & .559 & .07 & .13 & .43 & .20 \\
\hline $\mathrm{CT}$ & $\leftrightarrow$ & Peer empathy & .427 & .06 & .13 & .30 & .19 \\
\hline $\mathrm{CT}$ & $\leftrightarrow$ & $\mathrm{CP}$ & .547 & .05 & .10 & .44 & .16 \\
\hline CT & $\leftrightarrow$ & Impulse control & .672 & .08 & .15 & .52 & .23 \\
\hline $\mathrm{CT}$ & $\leftrightarrow$ & Emotional control & .519 & .07 & .13 & .39 & .20 \\
\hline Problem-solving & $\leftrightarrow$ & Peer empathy & .437 & .06 & .12 & .32 & .18 \\
\hline Problem-solving & $\leftrightarrow$ & $\mathrm{CP}$ & .477 & .05 & .09 & .39 & .14 \\
\hline Problem-solving & $\leftrightarrow$ & Impulse control & .575 & .07 & .13 & .44 & .20 \\
\hline Problem-solving & $\leftrightarrow$ & Emotional control & .447 & .06 & .11 & .33 & .17 \\
\hline Peer empathy & $\leftrightarrow$ & $\mathrm{CP}$ & .580 & .05 & .10 & .48 & .16 \\
\hline Peer empathy & $\leftrightarrow$ & Impulse control & .495 & .07 & .13 & .36 & .20 \\
\hline Peer empathy & $\leftrightarrow$ & Emotional control & .219 & .05 & .09 & .13 & .14 \\
\hline $\mathrm{CP}$ & $\leftrightarrow$ & Impulse control & .449 & .05 & .10 & .35 & .15 \\
\hline $\mathrm{CP}$ & $\leftrightarrow$ & Emotional control & .208 & .03 & .07 & .14 & .10 \\
\hline Impulse control & $\leftrightarrow$ & Emotional control & .439 & .06 & .12 & .32 & .18 \\
\hline
\end{tabular}

$\mathrm{CP}$, control of relationships with one's peers; $\mathrm{CT}$, control of relationship with one's teacher.

teacher doesn't see it in class" was revised to "I do something else in class without the teacher's knowledge". One item was revised in the area of control of relationships with one's peers.
Specifically, in the item "I cooperate well at joint work when I collaborate with friends", "joint work" was modified to "group activity". One item was revised in the peer empathy area; 
namely, "I don't express myself when I do well on an exam" was modified to "I show off to my friends when my test scores are good". In addition, one item was revised in the area of emotional control. Specifically, "I can't control my emotions when I feel good or bad" was changed to "I express myself immediately when I feel good or bad". In total, five items were revised.

This scale targets fifth- to sixth-grade elementary school students, and participants respond on a 5-point Likert scale. Higher scores indicate better self-control competency.

\section{DISCUSSION}

\section{Components of Late-school-aged Children's Self- control Competency}

Through the literature review and focus group interviews for scale development, the following five attributes of selfcontrol were found: interpersonal relations, impulse control, task solving, deliberation, and emotional control, and the preliminary scale was configured accordingly. In this study, the following six attributes were used to evaluate self-control: control of relationship with one's teacher, problem-solving, peer empathy, control of relationships with one's peers, impulse control, and emotional control. There were 92 preliminary items. Content validity assessment was conducted with 63 initial items, through content validity verification. The final scale was 13 questions.

The importance of interpersonal relations in this scale is consistent with previous studies showing that social aspects and education in schools are major factors related to self-control [4,27]. A previous study [12] found two attributes: friendrelated factors and teacher-related factors. In this study, control of relationship with one's teacher and control of relationships with one's peers showed different attributes. However, the items focused on cooperation in school tasks rather than relationships with friends.

Problem-solving is completed in order to perform a given task. Based on the field survey, items such as "I read long books to the end" and "I carry out the plans I make for doing well on exams" were included. The items included in the final scale did not show noteworthy differences from items in previous studies dealing with completing tasks or achieving goals [10-12]. For late-school-aged children, "problem-solving" meant enduring boring tasks, being able to complete difficult problems, or consistently practicing a plan. Validity refers to whether a scale reflects and measures the concept that it is intended to measure [21]. The absence of a significant difference between previous studies and the results of this study, this suggests that problem-solving is a valid attribute for measuring self-control.

Impulse control involves resisting temptation or impulses as part of self-control. Scales measuring the attribute of immediate satisfaction-seeking contain items related to impulse control such as "I want to do or have something I want to do immediately" and "I can't stand waiting for what I want to say" $[4,6]$. The items that were developed through the focus group interview were "I have to do my homework now, but I can't stand it when my brothers and sisters are watching TV" and "Don't eat food that the doctor says not to eat when I'm sick". These items were included in the original survey. Eighteen of the 63 initial items dealt with impulse control. Two items were "Although I want to play longer than the set time, I can stop playing the game (on the computer)" and "I tend to follow time limits for using my smartphone". This indicates that the impulses of late-school-aged children were directed more towards using smart devices than towards eating food, playing with friends, and watching TV. This finding also suggests that smart devices (and games) are a newly emerging impulse control factor that is relevant in current conditions. In addition, these two items were not included in previous scales.

Emotional control can be divided into peer empathy and control of one's emotions. In previous studies, anger control was a sub-factor of self-control that corresponded to negative emotions $[10,11]$. The characteristics of being unable to control anger or being angry were generally expressed as characteristics of self-control. This is consistent with previous studies showing that rapid emotional changes negatively affect selfcontrol [28]. However, in the developed scale, emotional control had a broader range of properties, including peer empathy and emotions other than anger. Empathy may therefore be related to self-control. Further research is needed to confirm the validity of empathy as a component of self-control.

Deliberation was initially found to be a sub-attribute of self-control, as opposed to personality traits and impulsiveness in previous studies [12]. However, deliberation was excluded from the final attributes in the verification of construct validity in EFA. This is a difference from previous studies, and further research is required. Although the fifth and sixth grades of elementary school are an important period of a child's development, deliberation varied across individuals and did not appear to be a common characteristic for measuring self-control.

As discussed earlier, interpersonal relationships as a subfactor of self-control were divided into control of relationship with one's teacher and control of relationships with one's peers. The emotional control attribute was divided into peer empathy and emotional control. Deliberation was not ultimately included as an attribute of self-control. 


\section{Measurement Scale Development Process, Validity Verification, and Reliability Verification}

Content validity was confirmed through expert validation. Since content validity is based on the subjective judgment of the content expert, care is needed when selecting an expert [29]. The CVI was assessed through a structured questionnaire [30]. In this study, EFA and CFA were performed to verify the construct validity. The validity of the exploratory method and the confirmatory method was ensured by the participation of multiple individuals with different backgrounds [21]. In the CFA, AVE and CR were checked to confirm convergence between the measured variable and the latent variable. Convergence validity was confirmed for the properties of control of relationship with one's teacher, problemsolving, peer empathy, control of relationships with one's peers, impulse control, and emotional control. The AVE and $\mathrm{CR}$ of emotional control were close to the reference point. For CFA, it is considered necessary to conduct repeated studies to ensure validity in the area of emotional regulation, which did not exceed the reference point.

The concurrent validity criterion was satisfied, and the conditions of internal consistency reliability and test-retest reliability were satisfied. As a result of testing the scale, the reliability and validity of the self-control competency measurement scale were verified.

\section{Significance of Developing Self-control Scales for Late- school-aged Children}

This scale was developed with an appropriate number of items and measurement time to measure self-control in lateschool-aged children. The time required to complete the scale was less than 5 minutes. In addition, the scale was developed to include easily comprehensible phrases that participants can respond to according to the level of understanding of lateschool-aged children. In the development stage, opinions of the target group were collected through focus group interviews of late-school-aged children.

Among the items that were finally reflected, "I tend to follow time limits for using my smartphone" was chosen to directly reflect the group interview, and the item in the group interview, "Although I want to play longer than the set time, I can stop playing the game (on the computer)" was corrected through the content validity process. In addition, the items were refined to reflect the terms used in the field so that late-school-aged children could respond easily. This study is meaningful in that it developed a scale to evaluate self-control in late-school-aged children by collecting and analyzing data through field surveys and a literature review.

\section{CONCLUSION}

This study was conducted to develop a self-reported measurement scale for self-control in late-school-aged children and to verify its reliability and validity. The scale developed through this study consisted of 13 items with six attributes. There were three items for control of relationship with one's teacher, two items for problem-solving, two items for peer empathy, two items for control of relationships with one's peers, two items for impulse control, and two items for emotional control.

This scale included various attributes to measure self-control, a complex concept, in late-school-aged children (in fifth to sixth grade in elementary school). The final scale is composed of short sentences that elicit clear answers. In addition, it reflects terms used by current late-school-aged children. In particular, the items in the impulse control area are composed of items about smartphones (games) that have not been included in the existing scales, reflecting the current elementary school scene. The scale developed in this study is expected to provide practical help to more clearly and accurately evaluate self-control in late-school-aged children. Since this scale is for students in the fifth to sixth grades of elementary school, it is necessary to consider vocabulary and comprehension by grade when applied to other ages.

\section{Conflict of interest}

No existing or potential conflict of interest relevant to this article was reported.

\section{Data availability}

Please contact the corresponding author for data availability.

\section{REFERENCES}

1. Willems Y, Boesen N, Li J, Finkenauer C, Bartels M. The heritability of self-control: A meta-analysis. Neuroscience and Biobehavioral Reviews. 2019;100:324-334.

https://doi.org/10.1016/j.neubiorev.2019.02.012

2. Chen Z, Liu P, Zhang C, Feng T. Brain morphological dynamics of procrastination: The crucial role of the self-control, emotional, and episodic prospection network. Cerebral Cortex. 2020;30(5):2834-2853. https://doi.org/10.1093/cercor/bhz278

3. Hockenberry MJ, Wilson D. Wong's nursing care of infants and children. 11th ed. St. Louis, MO: Elsevier Inc; 2019. 8-23.

4. Gottfredson MR, Hirschi T. A general theory of crime. Palo Alto, CA: Stanford University Press; 1990. p. 85-122.

5. Miller R, Frohnwieser A, Schiestl M, McCoy DE, Gray RD, Taylor 
$\mathrm{AH}$, et al. Delayed gratification in New Caledonian crows and young children: Influence of reward type and visibility. Animal Cognition. 2020;23(1):71-85.

https://doi.org/10.1007/s10071-019-01317-7

6. Nam HM, OkSW. The effects of psychological family environment, self-control and friend characteristics of middle school students on their problem behaviors. Family and Environment Research. 2001; 39(7):37-58.

7. Moffitt TE, Arseneault L, Belsky D, Dickson N, Hancox RJ, Harrington $\mathrm{HL}$, et al. A gradient of childhood self-control predicts health, wealth, and public safety. Proceedings of the National Academy of Sciences. 2011;108(7):2693-2698.

https://doi.org/10.1073/pnas.1010076108

8. Strayhorn JM. Self-control: Theory and research. Journal of the American Academy of Child and Adolescent Psychiatry. 2002;41 (1):7-16. https://doi.org/10.1097/00004583-200201000-00006

9. Duckworth AL, Kern ML. A meta-analysis of the convergent validity of self-control measures. Journal of Research in Personality. 2011;45 (3):259-268. https://doi.org/10.1016/j.jrp.2011.02.004

10. Grasmick HG, Tittle CR, Bursik RJ, Arneklev BJ. Testing the core empirical implications of gottfredson and hirschi's general theory of crime. Journal of Research in Crime and Delinquency. 1993;30(1): 5-29. https://doi.org/10.1177/0022427893030001002

11. Tangney JP, Baumeister RF, Boone AL. High self-control predicts good adjustment, less pathology, better grades, and interpersonal success. Journal of Personality. 2004;72(2):271-324. https://doi.org/10.1111/j.0022-3506.2004.00263.x

12. Lee KN. The study for the development of child self-control rating scale. Korean Journal of the Human Development. 2000;7(1): 99-120.

13. Silver L. Smartphone ownership is growing rapidly around the world, but not always equally: In emerging economies, technology use still much more common among young people and the well-educated [Internet]. Washington D.C: Pew Research Center; 2019 [cited 2020 October 2]. Available from: https://www.pewresearch.org/global/2019/02/05/smartphone -ownership-is-growing-rapidly-around-the-world-but-not-always -equally/

14. Hong HG, Kim HS, Kim JH, Kim JH. Validity and reliability validation of the Korean version of the Brief Self-Control Scale (BSCS). Korean Journal of Psychology: General. 2012;31(4):1193-1210.

15. DeVellis RF. Scale development: Theory and applications. 4th ed. New York, NY: Sage publications; 2017.

16. Swartz-Barcott D, Kim H. An expansion and elaboration of the hybrid model of concept development. In: Rodgers BL, Knafl KA, editors. Concept development in nursing. Philadelphia, PA: WB Saunders; 2000.

17. Wei D, Brigell R, Khadka A, Perales N, Fink G. Comprehensive school-based health programs to improve child and adolescent health: Evidence from Zambia. PLOS One. 2019;14(5):e0217893. https://doi.org/10.1371/journal.pone.0217893

18. Polit DF, Beck CT. The content validity index: Are you sure you know what's being reported? Critique and recommendations. Research in Nursing and Health. 2006;29(5):489-497. https://doi.org/10.1002/nur.20147

19. Gray JR, Grove SK, Sutherland S. Burns and grove's the practice of nursing research: Appraisal, synthesis, and generation of evidence. 8th ed. St. Louis, MO: WB Saunders company Philadelphia, PA; 2017. p. 373-383, 411-415, 561.

20. Bujang MA, Baharum N. A simplified guide to determination of sample size requirements for estimating the value of intraclass correlation coefficient: A review. Archives of Orofacial Sciences. 2017;12(1):1-11.

21. Lee EO, Lim NY, Park HA, Lee IS, Bae JY, Lee SM. Nursing research and statistical analysis. Seoul: Soomoonsa; 2009.

22. Jang IS, Park S. Factors affecting on smartphone addiction according to the classification of addiction-risk groups among college students: A focus on self-control. Korean Journal of Adult Nursing. 2015;27(6):634-643. https://doi.org/10.7475/kjan.2015.27.6.634

23. Kang HC. A guide on the use of factor analysis in the assessment of construct validity. Journal of Korean Academy of Nursing. 2013;43 (5):587-594. https://doi.org/10.4040/jkan.2013.43.5.587

24. Hair JF, Black WC, Babin BJ, Anderson RE. Multivariate data analysis. 7th ed. London: Pearson Education; 2014. p. 89-150.

25. Shi Y, Lenzi M, An R. Cannabis liberalization and adolescent cannabis use: A cross-national study in 38 countries. PLoS One. 2015;10(11):e0143562. https://doi.org/10.1371/journal.pone.0143562

26. Roh KS. Statistical analysis of the thesis: SPSS \& AMOS 21. Seoul: Hanbit Academy Inc.; 2014. p. 264-320.

27. Buker H. Formation of self-control: Gottfredson and hirschi's general theory of crime and beyond. Aggression and Violent Behavior. 2011;16(3):265-276. https://doi.org/10.1016/j.avb.2011.03.005

28. Chester DS, Lynam DR, Milich R, Powell DK, Andersen AH, DeWall CN. How do negative emotions impair self-control? A neural model of negative urgency. NeuroImage. 2016;132:43-50. https://doi.org/10.1016/j.neuroimage.2016.02.024

29. Lee K, Shin S. Validity of instrument development research in Korean nursing research. Journal of Korean Academy of Nursing. 2013;43(6):697-703. https:// doi.org/10.4040/jkan.2013.43.6.697

30. Lynn MR. Determination and quantification of content validity. Nursing Research. 1986;35(6):382-386. https://doi.org/10.1097/00006199-198611000-00017 